\title{
Astragaloside IV Enhances Cisplatin Chemosensitivity in Non-Small Cell Lung Cancer Cells Through Inhibition of B7-H3
}

\author{
Cheng-Shi He ${ }^{a}$ Yi-Cheng Liu ${ }^{b}$ Zhi-Peng Xuc Peng-Chen Daid ${ }^{c}$ Xiao-Wei Chen ${ }^{e}$ \\ De-Hai Jin ${ }^{f}$
}

${ }^{a}$ Teaching Hospital of Chengdu University of Traditional Chinese Medicine, Chengdu, bepartment of ICU, Pengzhou Hospital of Traditional Chinese Medicine, Pengzhou, cPengzhou Hospital of Traditional Chinese Medicine, Pengzhou, ${ }^{\mathrm{C} C h e n g d u}$ University of Traditional Chinese Medicine, Chengdu, ePengzhou Hospital of Traditional Chinese Medicine, Pengzhou, 'Department of Respiration, Pengzhou Hospital Of Traditional Chinese Medicine, Pengzhou, China

\section{Key Word}

Non-small cell lung cancer $•$ Chemoresistance $•$ Astragaloside IV $•$ B7-H3

\begin{abstract}
Background: Chemoresistance is a major obstacle to successful chemotherapy for human nonsmall cell lung cancer (NSCLC). Astragaloside IV, the component of Astragalus membranaceus, has been reported to exhibit anti-inflammation, anti-cancer and immunoregulatory properties. In the present study, we investigated the role of astragaloside IV in the chemoresistance to cisplatin in NSCLC cells. Methods: We established astragaloside IV-suppressed NSCLC cell lines including A549, HCC827, and NCI-H1299 and evaluated their sensitivity to cisplatin in vitro. In addition, we examined the mRNA and protein levels of $\mathrm{B} 7-\mathrm{H} 3$ in response to cisplatin-based chemotherapy. Results: We showed that high doses of astragaloside IV $(10,20,40 \mathrm{ng} / \mathrm{ml})$ inhibited NSCLC cell growth, whereas low concentrations of astragaloside IV $(1,2.5,5 \mathrm{ng} / \mathrm{ml})$ had no obvious cytotoxicity on cell viability. Moreover, combined treatment with astragaloside IV significantly increased chemosensitivity to cisplatin in NSCLC cells. On the molecular level, astragaloside IV co-treatment significantly inhibited the mRNA and protein levels of B7-H3 in the presence of cisplatin. In addition, ectopic expression of $\mathrm{B} 7-\mathrm{H} 3$ diminished the sensitization role of astragaloside IV in cellular responses to cisplatin in NSCLC cells. Conclusion: These results demonstrate that astragaloside IV enhances chemosensitivity to cisplatin via inhibition of $\mathrm{B} 7-\mathrm{H} 3$ and that treatment with astragaloside IV and inhibition of $\mathrm{B} 7-\mathrm{H} 3$ serve as potential therapeutic approach for lung cancer patients.

(C) 2016 The Author(s)

Published by S. Karger AG, Basel
\end{abstract}

C.-S. He and Y.-C. Liu contributed equally to this work.

Yi-Cheng Liu Department of ICU, Pengzhou Hospital of Traditional Chinese Medicine, 396 South Street, Pengzhou, 611930 (China)

Tel. +86-013547913664, E-Mail lyichengl@sina.com 


\section{Cellular Physiology Cell Physiol Biochem 2016;40:1221-1229 \begin{tabular}{l|l} 
and Biochemistry Published online: December 14, 2016 & $\begin{array}{l}\text { (c) } 2016 \text { The Author(s). Published by S. Karger AG, Basel } \\
\text { www.karger.com/cpb }\end{array}$
\end{tabular} \\ He et al.: Astragaloside IV Enhances Chemosensitivity to Cisplatin in NSCLC}

\section{Introduction}

Non-small cell lung cancer (NSCLC) is the leading cause of cancer-related mortality worldwide with a lower overall 5-year survival rate compared with other types of cancer [1]. Availability of treatment strategies for NSCLC includes conventional surgery, radiotherapy, immunotherapy, chemotherapy, and a combination of these therapies [2, 3]. However, resistance to anti-cancer agents has become a great challenge for NSCLC treatment. Thus, it is important to focus on cancer-specific molecular changes and develop new and effective targeted therapies in clinical practice.

B7-H3, a member of the B7 family, is broadly expressed on transcriptional level in lymphoid and nonlymphoid organs and complicates the immune response by regulation of co-stimulatory and co-inhibitory pathways $[4,5]$. Several studies have suggested that B7-H3 is also present in certain types of human cancer and plays critical roles in carcinogenesis and tumor progression [6]. Up-regulation of B7-H3 occurs in a wide range of cancers, such as prostate cancer, lung cancer, colorectal carcinoma, pancreatic cancer, ovarian carcinoma and gastric cancer [7-12]. These observations demonstrate that overexpression of B7-H3 may indicate an aggressive biologic role in carcinogenesis. Accordingly, inhibition of B7-H3 expression effectively suppresses tumor cell growth, migration and metastasis, suggesting that B7-H3 is a potential therapeutic target in cancer treatment $[13,14]$.

Astragalus membranaceus is commonly used in Traditional Chinese Medicine to treat a variety of diseases [15]. Astragaloside IV, the component of Astragalus membranaceus, exhibits anti-oxidant, anti-cancer and neuro-protective properties [16]. In the current study, we investigated the tumor suppressive effects of astragaloside IV combined with B7-H3 in NSCLC cells.

\section{Materials and Methods}

\section{Cell culture and reagents}

The human NSCLC cell lines including A549, HCC827, and NCI-H1299 were purchased from the ATCC (Manassas, VA, USA). Astragaloside IV and cisplatin were purchased from Sigma-Aldrich (St. Louis, MO, USA). All cells were maintained at $37^{\circ} \mathrm{C}$ in $5 \% \mathrm{CO}_{2}$ incubator and cultured in Dulbecco's modified Eagle's medium (DMEM) supplemented with $10 \%$ fetal bovine serum (FBS) in an atmosphere containing $5 \% \mathrm{CO}_{2}$ at $37{ }^{\circ} \mathrm{C}$.

\section{Cell viability}

Cell viability was determined by CCK- 8 assay. To be brief, cultured NSCLC cells were seeded into 96-well plates at the density of $4 \times 10^{4}$ (cells/well). Then $10 \mu \mathrm{L} /$ well CCK8 solution (Beyotime, Nantong, China) was added and incubated in dark at $37^{\circ} \mathrm{C}$ for another $2 \mathrm{~h}$. The absorbance was determined with the wavelength of $490 \mathrm{~nm}$.

Apoptosis rate was measured by flow cytometry (FCM) analysis using propidium iodide (PI) apoptosis detection. To be brief, after treatment with cisplatin alone or in combination with astragaloside IV, the three human cell lines were washed with PBS, suspended by trypsinization, harvested by centrifugation $\left(4^{\circ} \mathrm{C}\right.$, $3000 \mathrm{RPM}, 5 \mathrm{~min}$ ) and resuspended in $400 \mu \mathrm{l}$ binding buffer at a concentration of $9 \times 105 \mathrm{cells} / \mathrm{ml}$, and then $10 \mu \mathrm{l}$ PI was added into the above solution for $5 \mathrm{~min}$ in dark $\left(4^{\circ} \mathrm{C}\right)$ before a further addition of $600 \mu \mathrm{l} \mathrm{PBS}$. Apoptosis rate was assessed by FCM analysis and 10,000 events were recorded for each FCM analysis.

Plasmid construction and transfection

The cDNA fragment encoding B7-H3 was isolated with Takara RNA PCR kit (Takara, Japan) using total RNAs. PCR products were cloned into pcDNA3.1 (+) (Invitrogen, Carlsbad, CA). Cells were transfected with plasmid encoding B7-H3 using Lipofectamine 2000 (Invitrogen) according to the manufacturer's protocol. The transfection medium (Opti-MEM; Gibco) was replaced with complete medium $12 \mathrm{~h}$ after transfection, and the cells were incubated for the indicated times. 


\section{Cellular Physiology Cell Physiol Biochem 2016;40:1221-1229 \begin{tabular}{l|l} 
and Biochemistry & DOI: 10.1159/000453175 \\
Published 2016 The Author(s). Published by S. Karger AG, Basel \\
www.karger.com/cpb
\end{tabular}}

He et al.: Astragaloside IV Enhances Chemosensitivity to Cisplatin in NSCLC

Total RNAs were isolated from tissues or cells by TRIzol reagent, and reverse transcriptions were performed by Takara RNA PCR kit (Takara, Japan) according to the manufacturer's instructions. In order to quantify the transcripts of the interest genes, real-time PCR was performed using a SYBR Green Premix Ex Taq ((Takara, Tokyo, Japan) on ABI 7500 system (Applied Biosystems, Foster, CA, USA) with GAPDH used as the endogenous control.

\section{Western blot}

Cells were lysed with RIPA lysis buffer (Beyotime, Nantong, China), and protein concentration was quantified with Pierce BCA Protein Assay Kit (Thermo, USA). Protein samples were separated by $10 \%$ SDS-PAGE and transferred to polyvinylidene difluoride (PVDF) membranes (Millipore, Billerica, MA, USA). The membranes were then incubated with anti-B7-H3 (Cell Signaling Technology, USA) antibodies at $4^{\circ} \mathrm{C}$ overnight. The membranes were washed three times with TBST prior to incubation with the appropriate HRP-conjugated secondary antibodies (Cell Signaling Technology, USA). The membranes were detected by chemiluminescence (GE Healthcare, Piscataway, NJ, USA).

\section{Statistical analysis}

Each experiment was performed in triplicate, and repeated at least three times. All the data were presented as means \pm SD and treated for statistics analysis by SPSS program. Comparison between groups was made using ANOVA and $\mathrm{P}<0.05$ was considered to indicate a statistically significant result.

\section{Results}

Effects of astragaloside IV on NSCLC cell viability

In order to determine the cytotoxic effects of astragaloside IV on NSCLC cells, CCK-8 assay was performed in three NSCLC cell lines exposed to astragaloside IV and cisplatin in different concentrations ranging from $0 \sim 40 \mathrm{ng} / \mathrm{ml}$. Results showed that low doses of astragaloside IV $(1,2.5,5 \mathrm{ng} / \mathrm{ml})$ and cisplatin $(0.5,1,2.5 \mu \mathrm{M})$ had no obvious cytotoxicity in A549, HCC827, and NCI-H1299 cells. However, higher concentrations of astragaloside IV (10, $20,40 \mathrm{ng} / \mathrm{ml})$ and cisplatin $(5,10,20,40 \mu \mathrm{M})$ significantly reduced the viability of NSCLC cells (Fig. 1A-D).

Combined treatment with astragaloside IV and cisplatin induce apoptosis in NSCLC cells

We next used FCM analysis with PI staining to determine whether treatment with cisplatin alone or in combination with astragaloside IV induced apoptosis. Results showed

Fig. 1. Effects of astragaloside IV and cisplatin on NSCLC cell viability. Three human NSCLC cell lines including A549 (A), HCC827 (B), and NCI-H1299 (C) were incubated with astragaloside IV at different concentrations $(1,2.5,5,10$, $20,40 \mathrm{ng} / \mathrm{ml}$ ) for $48 \mathrm{~h}$. And this three NSCLC cell lines were incubated with cisplatin (D) at different concentrations $(0.5,1,2.5,5$, $10,20,40 \mathrm{ng} / \mathrm{ml}$ ) for $48 \mathrm{~h}$. Cell viability was measured using CCK-8 method. $* \mathrm{P}<0.05$.

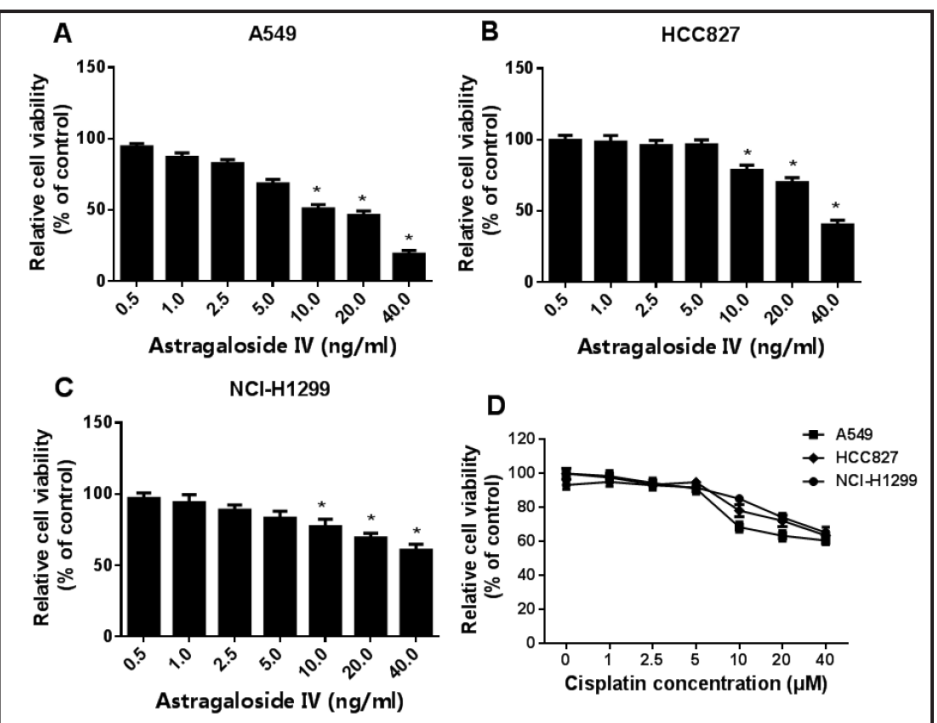




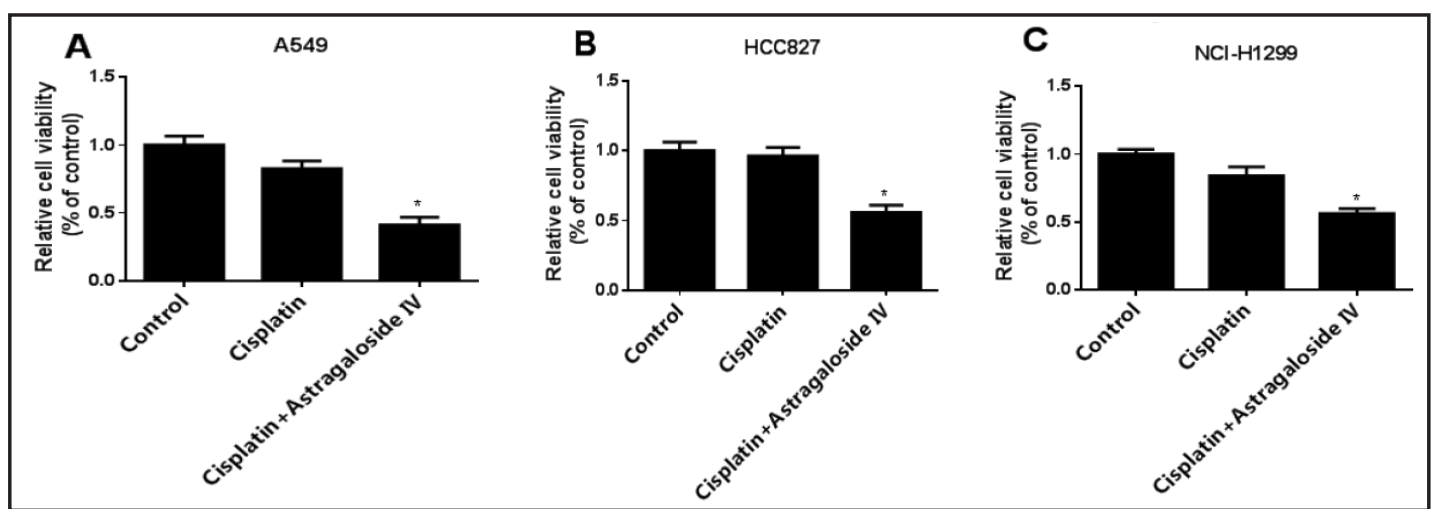

Fig. 2. Astragaloside IV sensitizes NSCLC cells to cisplatin. CCK-8 assay was used to determine the cell viability of A549 (A), HCC827 (B), and NCI-H1299 (C) cells after treatment with cisplatin alone or in combination with astragaloside IV. $* \mathrm{P}<0.05$.

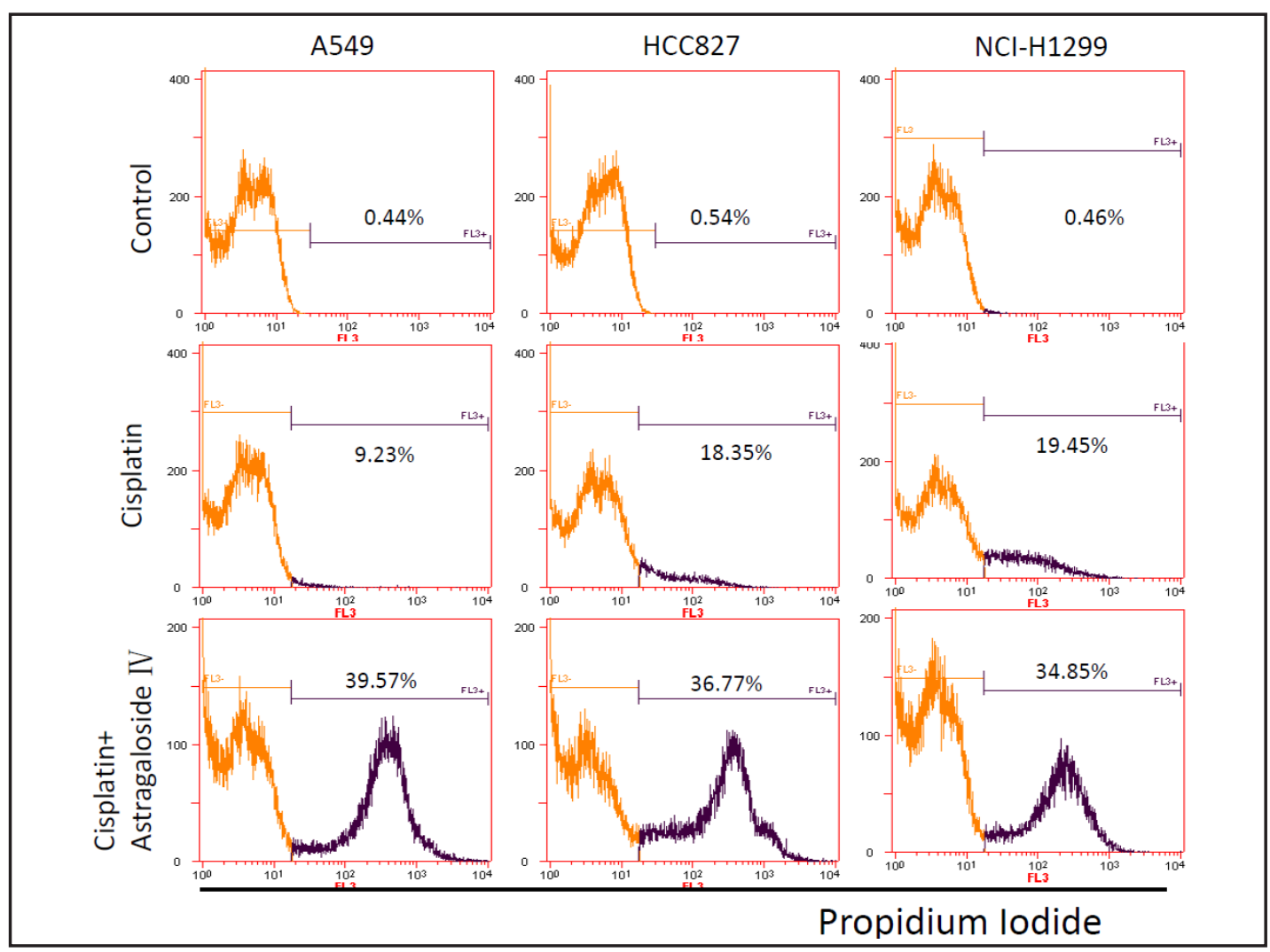

Fig. 3. Effects of astragaloside IV and cisplatin on NSCLC cell apoptosis by FCM analysis with PI staining. Three human NSCLC cell lines including A549, HCC827, and NCI-H1299 were incubated with cisplatin at 2.5 $\mu \mathrm{M}$ or in combination with astragaloside IV.

that 1 treatment with $2.5 \mu \mathrm{M}$ of cisplatin alone had no obvious apoptosis in A549, HCC827, and NCI-H1299 cells. However, after treatment with combination with $2.5 \mu \mathrm{M}$ of cisplatin and $5 \mathrm{ng} / \mathrm{mL}$ astragaloside IV, the percentageof apoptotic cells increased to $39.57 \%, 36.77$ $\%, 34.85 \%$ in A549, HCC827, and NCI-H1299 cells, respectively. (Fig. 2)

Combined treatment with astragaloside IV sensitizes NSCLC cells to cisplatin

Next, $5 \mathrm{ng} / \mathrm{ml}$ of astragaloside IV was chosen to examine its role in $2.5 \mu \mathrm{M}$ of cisplatin sensitivity in NSCLC cells. CCK-8 assay indicated that combined treatment with astragaloside 


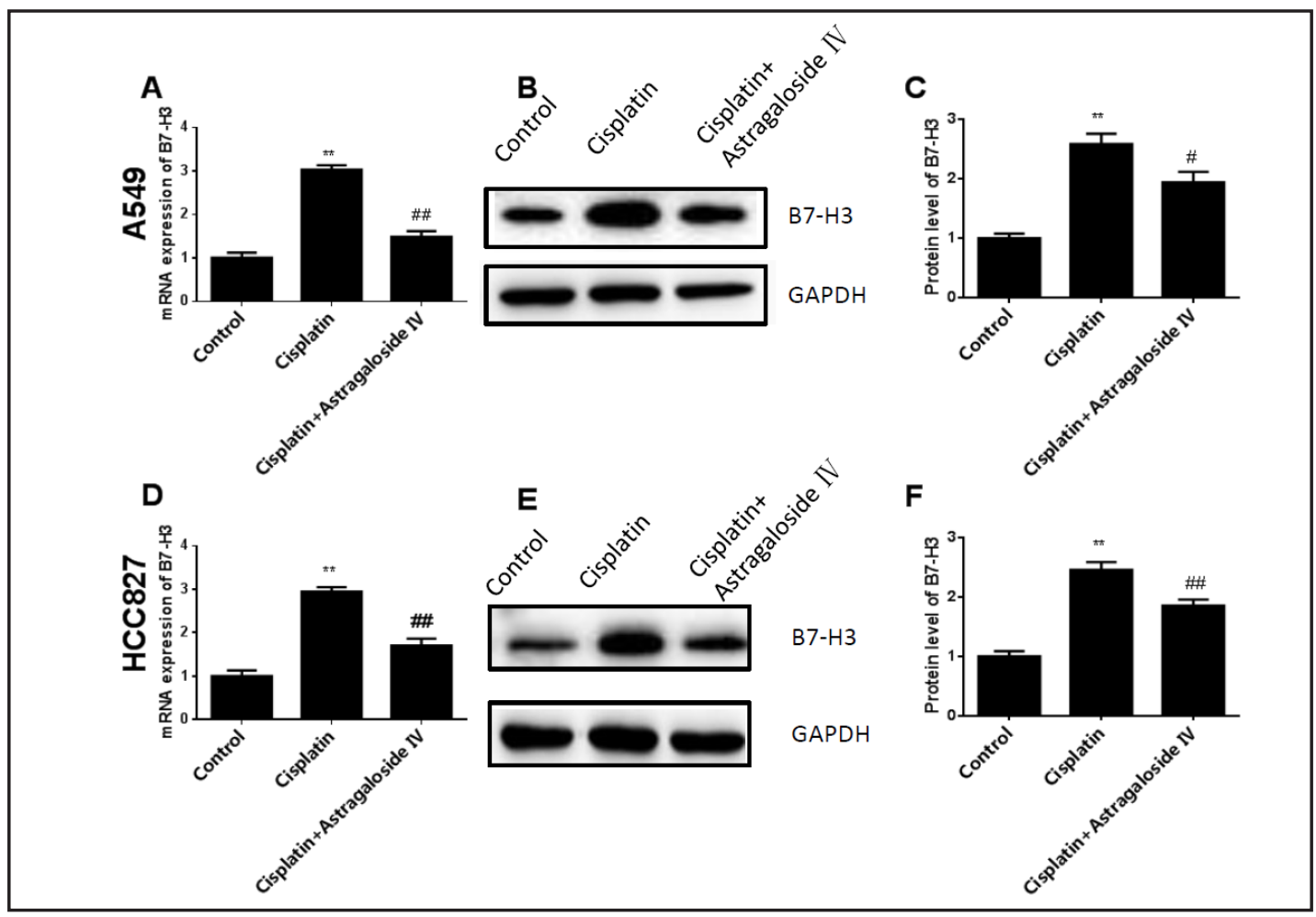

Fig. 4. Astragaloside IV co-treatment inhibits B7-H3 expression in NSCLC cells. Real time PCR was performed to measure the mRNA expression of B7-H3 in A549 (A) HCC827 (B) cells treated with cisplatin alone or in combination with astragaloside IV. The protein levels of B7-H3 in A549 (C), HCC827 (D) cells were assessed by western blot after exposure to cisplatin alone or in combination with astragaloside IV. The relative densities of B7-H3 in A549 (E), HCC827 (F) cells were corrected using GAPDH. Values represent means + SD at three experiments. $* \mathrm{P}<0.05$.

IV and cisplatin remarkably inhibited A549 cell viability compared with cisplatin-treated cells alone (Fig. 2A). In addition, similar cisplatin-sensitive role of astragaloside IV was also observed in HCC827 (Fig. 2B) and NCI-H1299 (Fig. 2C) cells. Taken together, these data suggest that astragaloside IV sensitizes NSCLC cells to cisplatin treatment.

Co-treatment with astragaloside IV and cisplatin induce apoptosis in NSCLC cells

We next used FCM analysis with PI staining to determine whether treatment with cisplatin alone or in combination with astragaloside IV induced apoptosis. Results showed that l treatment with $2.5 \mu \mathrm{M}$ of cisplatin alone had no obvious apoptosis in A549, HCC827, and NCI-H1299 cells. However, after treatment with combination with $2.5 \mu \mathrm{M}$ of cisplatin and $5 \mathrm{ng} / \mathrm{mL}$ astragaloside IV, the percentageof apoptotic cells increased to $39.57 \%, 36.77$ $\%, 34.85 \%$ in A549, HCC827, and NCI-H1299 cells, respectively. (Fig. 3)

\section{Co-treatment with astragaloside IV and cisplatin inhibits B7-H3 expression}

In order to elucidate the mechanism underlying the sensitization role of astragaloside IV, we examined the molecular changes in NSCLC cells before and after astragaloside IV co-treatment. Real time PCR showed that the mRNA expression of B7-H3 was significantly inhibited in A549 cells after co-administration with astragaloside IV (Fig. 4A). Moreover, combined treatment with astragaloside IV suppressed the protein expression of B7-H3 in A549 cells compared with the cisplatin-treated cells (Fig. 4C). In addition, the similar inhibitive effect of astragaloside IV on B7-H3 expression was also observed in HCC827 cells both on the mRNA and protein levels (Fig. 4B and D). These results imply that astragaloside IV sensitizes NSCLC cells to cisplatin through inhibition of B7-H3. 
Fig. 5. B7-H3 overexpression diminished the chemosensitization role of astragaloside IV in A549 cells. Plasmids encoding B7-H3 were transfected into A549 cells. $48 \mathrm{~h}$ after transfection, real time PCR and western blot were performed to detect the mRNA (A) and protein expression of B7-H3 (B, C), respectively. (D) After ectopic expression of B7-H3, CCK-8 assay was used to determine cell viability in the presence of cisplatin alone or in combination with astragaloside IV. ${ }^{* *} \mathrm{P}<0.01$ was compared to control, \#\# $\mathrm{P}<0.01$ was compared to cisplatin group.

Fig. 6. B7-H3 overexpression diminished the chemosensitization role of astragaloside IV in HCC827 cells. Plasmids encoding B7-H3 were transfected into HCC827 cells. $48 \mathrm{~h}$ after transfection, real time PCR and western blot were performed to detect the mRNA (A) and protein expression of B7-H3 (B, C), respectively. (D) After ectopic expression of B7H3, CCK-8 assay was used to determine cell viability in the presence of cisplatin alone or in combination with astragaloside IV. ** $\mathrm{P}<0.01$ was compared to control, \#\# $\mathrm{P}<0.01$ was compared to cisplatin group.

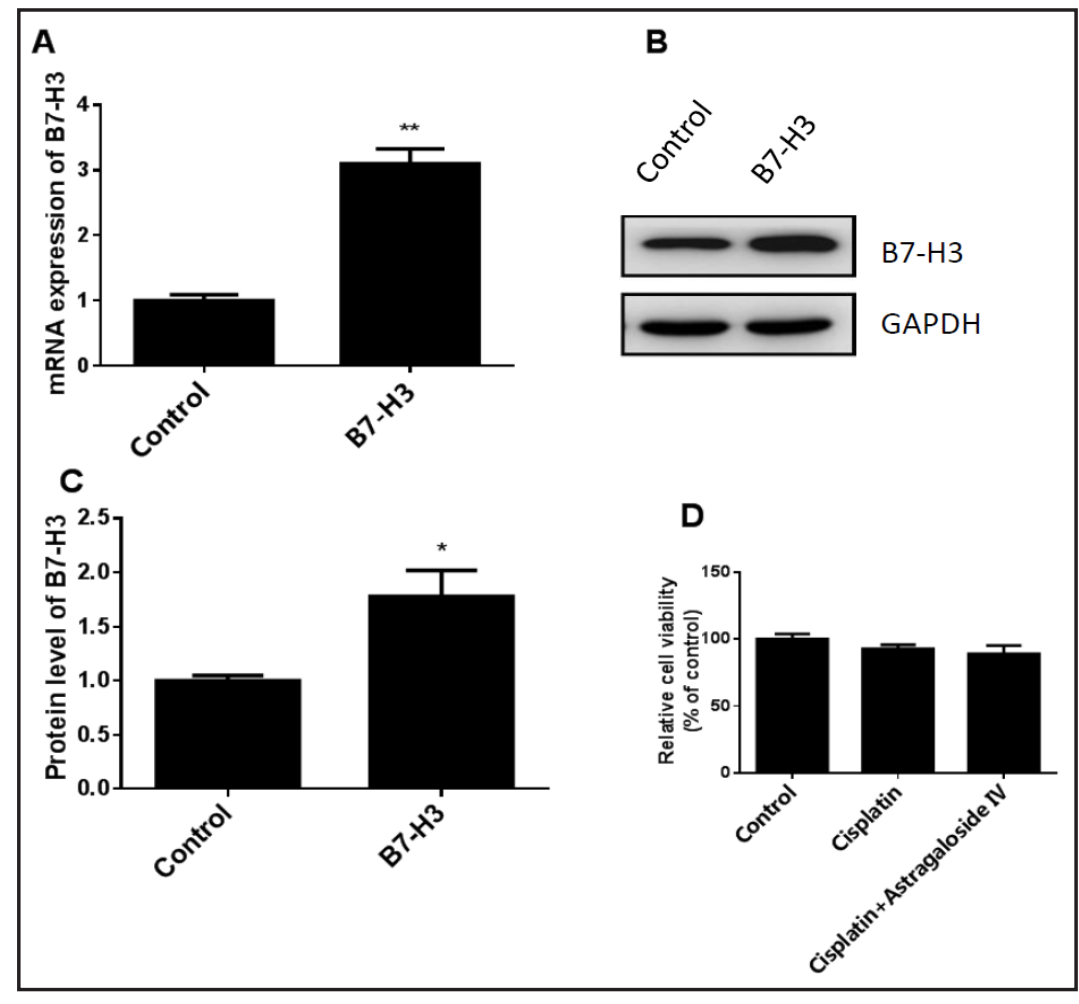

A

B
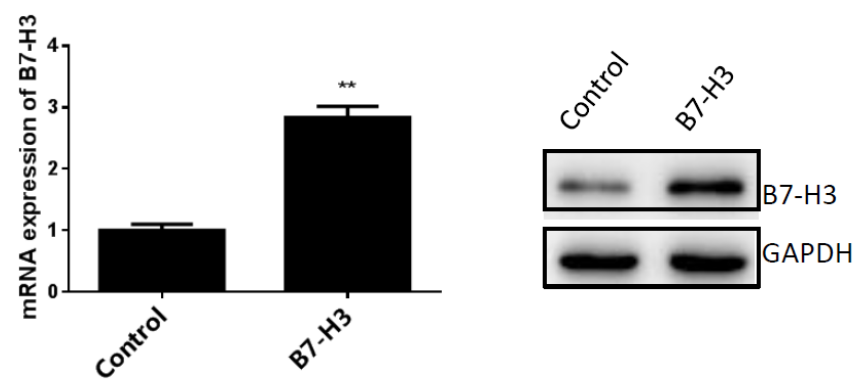

C

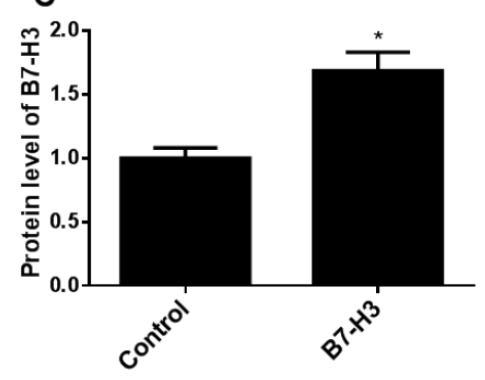

D

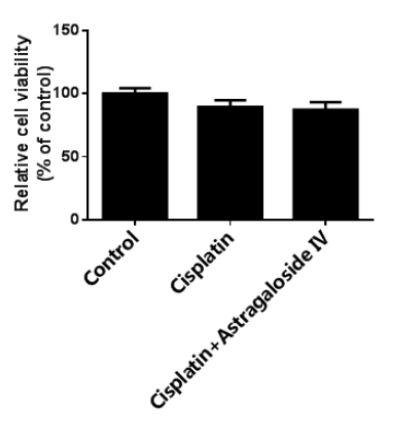

B7-H3 overexpression diminished the role of astragaloside IV in the sensitization to cisplatin

To determine the role of B7-H3 in the chemoresistance, we constructed the plasmid encoding B7-H3 and transfected it into A549 cells. Real time PCR showed that the mRNA expression of B7-H3 increased more than three-folds in B7-H3 plasmid-tranfected cells 
Fig. 7. B7-H3 overexpression diminished the chemosensitization role of astragaloside IV in NCI-H1299 cells. Plasmids encoding B7H3 were transfected into NCI-H1299 cells. $48 \mathrm{~h}$ after transfection, real time PCR and western blot were performed to detect the mRNA (A) and protein expression of $\mathrm{B} 7-\mathrm{H} 3$ (B, C) , respectively. (D) After ectopic expression of B7-H3, CCK-8 assay was used to determine cell viability in the presence of cisplatin alone or in combination with astragaloside IV. ${ }^{* *} \mathrm{P}<$ 0.01 was compared to control, \#\# $\mathrm{P}<0.01$ was compared to cisplatin group.

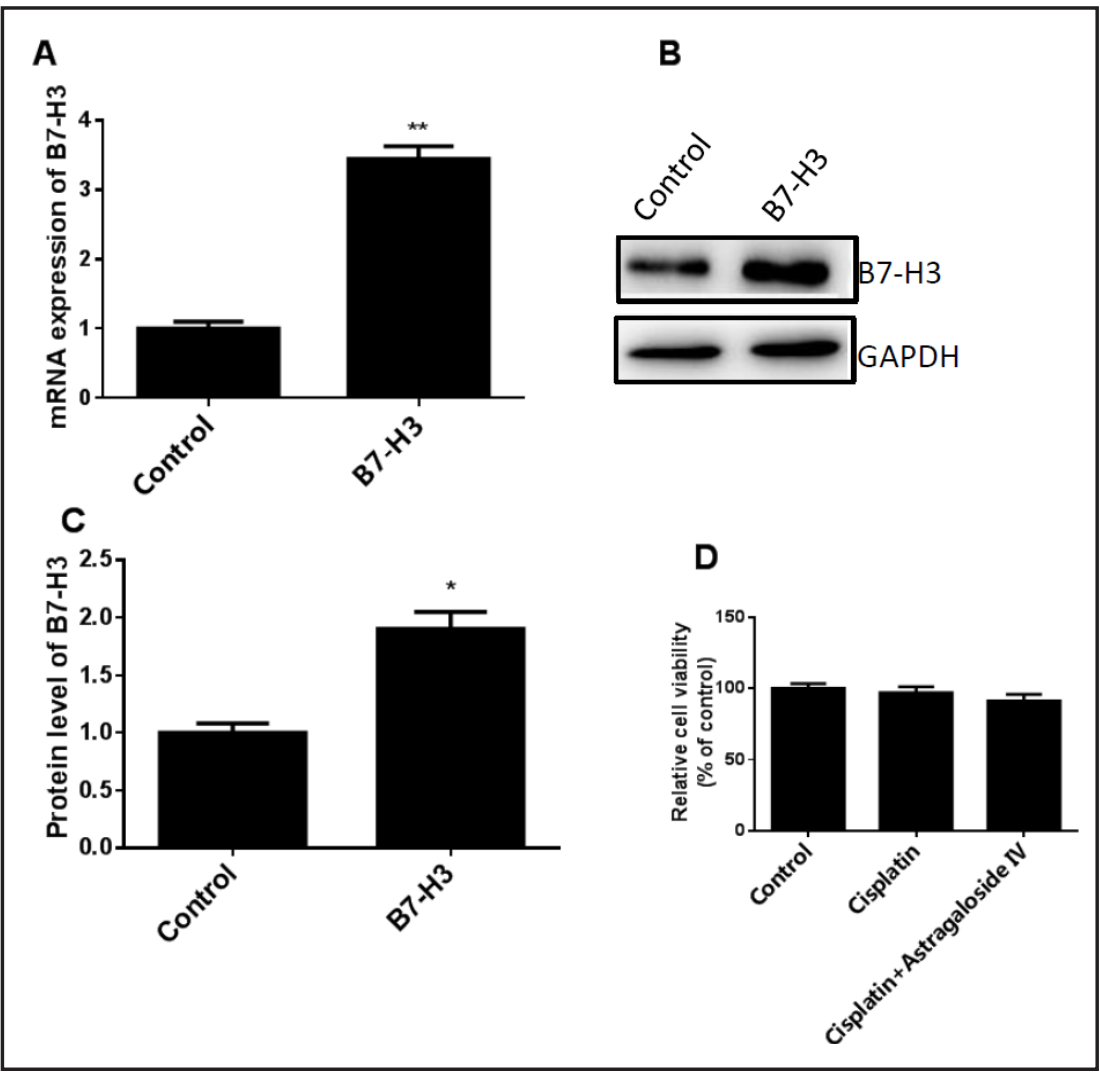

(Fig. 5A). Furthermore, the protein expression of B7-H3 was obviously increased in A549 cells transfected with plasmid encoding B7-H3 (Fig. 5B and C). As a result, we found that ectopic expression of B7-H3 diminished the sensitization role of astragaloside IV in cellular response to cisplatin (Fig. 5D). In addition, the similar effects of B7-H3 overexpression on the sensitization role of stragaloside IV in cellular response to cisplatin were also observed in HCC827 cells both on the mRNA and protein levels (Fig. 6 and Fig. 7). Taken together, these results demonstrate that astragaloside IV enhances the cisplatin cytotoxicity via regulation of B7-H3 in NSCLC cells.

\section{Discussion}

Acquisition of resistance to chemotherapeutic agents is a major cause of treatment failure during clinical treatment of malignant cells $[17,18]$. Development of potential anticancer drugs from traditional Chinese medicine is among the most important strategies in the field of cancer chemotherapy. In the current study, we found that astragaloside IV could potentiate the cisplatin cytotoxicity through inhibition of B7-H3 in NSCLC cells.

Astragaloside IV is a main component of Astragalus membranaceus, a commonly used medicinal plant in East Asia [19]. Previous studies have reported that astragaloside IV is a novel anti-inflammatory agent and may be used for the treatment of cardiovascular diseases [20]. Moreover, astragaloside II has been proved to be capable of reversing hepatoma multiple drug resistance through inhibition of mdr1 expression and mitogen-activated protein kinase (MAPK) signals [21]. In the current study, our results showed that high doses of astragaloside IV inhibited NSCLC cell growth, whereas low concentrations of astragaloside IV had no obvious cytotoxicity in A549, HCC827, and NCI-H1299 cells. In addition, we firstly found that combined treatment with astragaloside IV significantly increased the cisplatin 


\section{Cellular Physiology Cell Physiol Biochem 2016;40:1221-1229 \begin{tabular}{l|l|l|} 
DOI: 10.1159/000453175 & $\begin{array}{l}\text { (c) 2016 The Author(s). Published by S. Karger AG, Basel } \\
\text { www.karger.com/cpb }\end{array}$
\end{tabular} \\ He et al.: Astragaloside IV Enhances Chemosensitivity to Cisplatin in NSCLC}

sensitivity in NSCLC cells, suggesting the potential clinical application of astragaloside IV on patients resistant to anti-cancer agents.

B7-H3 was originally cloned from a dendritic cell cDNA library and is expressed at low levels in several normal lymphoid and peripheral tissues [22,23]. Recently, numerous studies have revealed that B7-H3 is abnormally up-regulated in a variety of cancers, whereas the B7-H4 protein is barely detected in the majority of normal human tissues [24,25]. In addition, overexpression of B7-H3 has been suggested to be positively correlated with tumor size, progression and prognosis [25]. For instance, Zang et al. and Roth et al. showed that B7-H3 is abundantly expressed in prostate cancer and associated with disease spread and poor outcome $[26,27]$. Sun et al. reported that B7-H3 expression was positively correlated with a more advanced tumor grade in colorectal cancer [28]. A recent study from Chen et al. demonstrated that induced expression of B7-H3 on the lung cancer cells and macrophages suppressed T-cell mediating anti-tumor immune response [29]. Furthermore, it is reported that inhibition of B7-H3 by siRNA significantly suppresses cell migration and invasion, enhances sensitivity to chemotherapeutic drugs in acute monocytic leukemia U937 cells [30]. In pancreatic carcinoma, it is suggested that silencing of B7-H3 increases gemcitabine sensitivity through induction of surviving-dependent apoptosis [31]. In our study, the mRNA and protein levels of B7-H3 were remarkably reduced in NSCLC cells treated with cisplatin and astragaloside IV, suggesting that astragaloside IV increased cisplatin sensitivity via downregulating B7-H3 expression. In order to confirm the role of B7-H3 in the chemoresistance, B7-H3 was ectopically expression in NSCLC cells. Consequently, we found that up-regulation of B7-H3 diminished the sensitization role of astragaloside IV in cellular responses to cisplatin.

In conclusion, our study demonstrates that astragaloside IV treatment increased cisplatin cytotoxicity in NSCLC cells through inhibition of B7-H3 expression. These findings suggest that combined treatment with astragaloside IV and inhibition of B7-H3 are potential therapeutic approach for patients with lung cancer.

\section{Disclosure Statement}

The authors declare that they have no competing interests.

\section{References}

1 Siegel RL, Miller KD, Jemal A: Cancer statistics, 2015. CA Cancer J Clin 2015;65:5-29.

2 O'Connor GT, Hatabu H: Lung cancer screening, radiation, risks, benefits, and uncertainty. JAMA 2012;307:2434-2435.

3 Silvestri GA, Rivera MP: Targeted therapy for the treatment of advanced non-small cell lung cancer: A review of the epidermal growth factor receptor antagonists. Chest 2005;128:3975-3984.

$4 \quad$ Hansen JD, Du Pasquier L, Lefranc MP, Lopez V, Benmansour A, Boudinot P: The B7 family of immunoregulatory receptors: A comparative and evolutionary perspective. Mol Immunol 2009;46:457472.

5 Collins M, Ling V, Carreno BM: The B7 family of immune-regulatory ligands. Genome Biol 2005;6:223.

6 Flies DB, Chen L: The new B7s: Playing a pivotal role in tumor immunity. J Immunother 2007;30:251-260.

7 Chavin G, Sheinin Y, Crispen PL, Boorjian SA, Roth TJ, Rangel L, Blute ML, Sebo TJ, Tindall DJ, Kwon ED, Karnes RJ: Expression of immunosuppresive B7-H3 ligand by hormone-treated prostate cancer tumors and metastases. Clin Cancer Res 2009;15:2174-2180.

8 Sun Y, Wang Y, Zhao J, Gu M, Giscombe R, Lefvert AK, Wang X: B7-H3 and B7-H4 expression in non-smallcell lung cancer. Lung Cancer 2006;53:143-151.

9 Sun J, Chen LJ, Zhang GB, Jiang JT, Zhu M, Tan Y, Wang HT, Lu BF, Zhang XG: Clinical significance and regulation of the costimulatory molecule B7-H3 in human colorectal carcinoma. Cancer Immunol Immunother 2010;59:1163-1171. 


\section{Cellular Physiology Cell Physiol Biochem 2016;40:1221-1229 \begin{tabular}{l|l|l|} 
DOI: 10.1159/000453175 & $\begin{array}{l}\text { (c) 2016 The Author(s). Published by S. Karger AG, Basel } \\
\text { www.karger.com/cpb }\end{array}$ \\
\hline Published online: December 14, 2016
\end{tabular}}

He et al.: Astragaloside IV Enhances Chemosensitivity to Cisplatin in NSCLC

10 Yamato I, Sho M, Nomi T, Akahori T, Shimada K, Hotta K, Kanehiro H, Konishi N, Yagita H, Nakajima Y: Clinical importance of B7-H3 expression in human pancreatic cancer. Br J Cancer 2009;101:1709-1716.

11 Zang X, Sullivan PS, Soslow RA, Waitz R, Reuter VE, Wilton A, Thaler HT, Arul M, Slovin SF, Wei J, Spriggs DR, Dupont J, Allison JP: Tumor associated endothelial expression of B7-H3 predicts survival in ovarian carcinomas. Mod Pathol 2010;23:1104-1112.

12 Wu CP, Jiang JT, Tan M, Zhu YB, Ji M, Xu KF, Zhao JM, Zhang GB, Zhang XG: Relationship between costimulatory molecule B7-H3 expression and gastric carcinoma histology and prognosis. World J Gastroenterol 2006;12:457-459.

13 Zhao J, Lei T, Xu C, Li H, Ma W, Yang Y, Fan S, Liu Y: MicroRNA-187, down-regulated in clear cell renal cell carcinoma and associated with lower survival, inhibits cell growth and migration though targeting B7-H3. Biochem Biophys Res Commun 2013;438:439-444.

$14 \mathrm{Xu} \mathrm{H}$, Cheung IY, Guo HF, Cheung NK: MicroRNA miR-29 modulates expression of immunoinhibitory molecule B7-H3: Potential implications for immune based therapy of human solid tumors. Cancer Res 2009;69:6275-6281.

15 Song JZ, Yiu HH, Qiao CF, Han QB, Xu HX: Chemical comparison and classification of Radix Astragali by determination of isoflavonoids and astragalosides. J Pharm Biomed Anal 2008;47:399-406.

16 Zhao M, Zhao J, He G, Sun X, Huang X, Hao L: Effects of astragaloside IV on action potentials and ionic currents in guinea-pig ventricular myocytes. Biol Pharm Bull 2013;36:515-521.

17 Yu M, Ocana A, Tannock IF: Reversal of ATP-binding cassette drug transporter activity to modulate chemoresistance: Why has it failed to provide clinical benefit? Cancer Metastasis Rev 2013;32:211-227.

18 Brown R, Curry E, Magnani L, Wilhelm-Benartzi CS, Borley J: Poised epigenetic states and acquired drug resistance in cancer. Nat Rev Cancer 2014;14:747-753.

19 Zhang A, Zheng Y, Que Z, Zhang L, Lin S, Le V, Liu J, Tian J: Astragaloside IV inhibits progression of lung cancer by mediating immune function of Tregs and CTLs by interfering with IDO. J Cancer Res Clin Oncol 2014;140:1883-1890.

20 Zhao J, Yang P, Li F, Tao L, Ding H, Rui Y, Cao Z, Zhang W: Therapeutic effects of astragaloside IV on myocardial injuries: Multi-target identification and network analysis. PLoS One 2012;7:e44938.

21 Huang C, Xu D, Xia Q, Wang P, Rong C, Su Y: Reversal of P-glycoprotein-mediated multidrug resistance of human hepatic cancer cells by Astragaloside II. J Pharm Pharmacol 2012;64:1741-1750.

22 Chapoval AI, Ni J, Lau JS, Wilcox RA, Flies DB, Liu D, Dong H, Sica GL, Zhu G, Tamada K, Chen L: B7-H3: A costimulatory molecule for T cell activation and IFN-gamma production. Nat Immunol 2001;2:269-274.

23 Sun M, Richards S, Prasad DV, Mai XM, Rudensky A, Dong C: Characterization of mouse and human B7-H3 genes. J Immunol 2002;168:6294-6297.

24 Sun J, Mao Y, Zhang YQ, Guo YD, Mu CY, Fu FQ, Zhang XG: Clinical significance of the induction of macrophage differentiation by the costimulatory molecule B7-H3 in human non-small cell lung cancer. Oncol Lett 2013;6:1253-1260.

25 Flies DB, Chen L: The new B7s: Playing a pivotal role in tumor immunity. J Immunother 2007;30:251-260.

26 Zang X, Thompson RH, Al-Ahmadie HA, Serio AM, Reuter VE, Eastham JA, Scardino PT, Sharma P, Allison JP: B7-H3 and B7x are highly expressed in human prostate cancer and associated with disease spread and poor outcome. Proc Natl Acad Sci U S A 2007;104:19458-19463.

27 Roth TJ, Sheinin Y, Lohse CM, Kuntz SM, Frigola X, Inman BA, Krambeck AE, McKenney ME, Karnes RJ, Blute ML, Cheville JC, Sebo TJ, Kwon ED: B7-H3 ligand expression by prostate cancer: A novel marker of prognosis and potential target for therapy. Cancer Res 2007;67:7893-7900.

28 Sun J, Chen LJ, Zhang GB, Jiang JT, Zhu M, Tan Y, Wang HT, Lu BF, Zhang XG: Clinical significance and regulation of the costimulatory molecule B7-H3 in human colorectal carcinoma. Cancer Immunol Immunother 2010;59:1163-1171.

29 Chen C, Shen Y, Qu QX, Chen XQ Zhang XG, Huang JA: Induced expression of B7-H3 on the lung cancer cells and macrophages suppresses T-cell mediating anti-tumor immune response. Exp Cell Res 2013;319:96102.

30 Zhang W, Wang J, Wang Y, Dong F, Zhu M, Wan W, Li H, Wu F, Yan X, Ke X: B7-H3 silencing by RNAi inhibits tumor progression and enhances chemosensitivity in U937 cells. Onco Targets Ther 2015;8:1721-1733.

31 Zhao X, Zhang GB, Gan WJ, Xiong F, Li Z, Zhao H, Zhu DM, Zhang B, Zhang XG, Li DC: Silencing of B7-H3 increases gemcitabine sensitivity by promoting apoptosis in pancreatic carcinoma. Oncol Lett 2013;5:805812. 